\title{
AGAMA DAN KERAGAMAN DALAM FILM INDONESIA DAN MALAYSIA
}

\author{
Mufdil Tuhri \\ Universitas Gadjah Mada, Yogyakarta ,55281, Indonesia \\ mufdiltuhri@gmail.com
}

\begin{abstract}
Article history:

Received : 2020-07-27

Revised : 2020-12-01

Accepted : 2020-12-21

Keywords:

Religion,

Diversity,

Film,

Indonesian,

Malaysian

This article elaborated the representation of religion and diversity in two Indonesian and Malaysian films. Both films portrayed the religious expression of society in the dominant structure of Islam as the majority religion in both countries. Both films investigated were new features in the context of popular culture development in both countries. Methodologically, this article compared two films, namely Indonesian Film 'Seeking Hilal' (2015) and Malaysian Film, 'Wayang' (2008). To analyze films, this article used the theory of representation proposed by Stuart Hall (1997). This article concluded that the two films showed the same polemic context between the conservative and modernist spectrum of Islam as the dominant religion in two countries.
\end{abstract}

Kata Kunci :

Agama,

Keragaman,

Film,

Indonesia,

Malayasia

\section{ABSTRAK}

Artikel ini membahas tentang representasi agama dan keragaman dalam dua film Indonesia dan Malaysia. Dua film ini sama-sama memotret ekspresi keberagamaan masyarakat dalam struktur dominan Islam sebagai agama mayoritas di kedua negara. Dua film yang teliti merupakan corak baru dalam konteks perkembangan budaya popular di kedua Negara. Secara metodologis, artikel ini membandingkan antara dua film yaitu Film Indonesia Mencari Hilal (2015) dan Film Malaysia, Wayang (2008). Untuk menganalisis film, artikel ini menggunakan teori Representasi oleh Stuart Hall (1997). Artikel ini berkesimpulan bahwa dua film tersebut menunjukkan konteks polemik yang sama antara spektrum konservatif dan modernis Islam sebagai agama dominan di dua negara.

\section{Pendahuluan}

Film mencari hilang merupakan

Kehidupan manusia dalam lingkup sosial tentu meninggalkan wujud budaya itu sendiri. Pada bagian sosial budaya dapat berupa interaksi, watak pada bagian organisasinya. Perbedaan budaya tentu menjadi sunatullah yang telah ada dan akan selalu ada. Indonesia dan Malaysia sebagai bangsa melayu tentu memiliki persamaan dan perbedaan. Indonesia dan Malaysia sebagai orang Melayu memiliki diskursus masingmasing tentu akan memunculkan kedinamisan budaya nya. Salah satu cara untuk menilai hal tersebut dapat kita telaah melalui film yang berlatar belakang gambaran budaya masyarakat. sebuah karya untuk memaparkan perbedaan dan mengusung sebuah pesan positif dalam menyikapi perbedaan yang ada. Sedangkan film wayang merupakan sebuah karya yang memberi pesan untuk melihat sebuah keteguhan dari keyakinan yang telah ada.

Sebagai bagian dari kajian media dan budaya, kajian film dianggap sebagai bagian esensial dari produk budaya (Dominic Strinati, 2005). Graeme berpendapat bahwa dalam mereview film dibutuhkan unsur utama teori linguistik dan antropologi yang berada di bawah payung strukturalisme. Strukturalisme menerima bahwa film diproduksi oleh pembuat film, tetapi juga 
menunjukkan bahwa pembuat film itu sendiri diproduksi oleh budaya. Teori strukturalisme telah sangat berguna dalam menghubungkan kembali film dengan budaya yang diwakilinya (Turner, 1988). Belajar tentang film adalah proses membaca teks dan memperdalam budaya masyarakat guna memperoleh pengetahuan dan pemahaman tentang apa yang dikatakan sutradara sebagai pembuat film, film sebagai produk budaya dan representasi dalam kehidupan nyata. Salah satu bentuk pembacaan keberagaman dalam Essay film Asia Selatan akan mengkaji perbandingan konsep representasi agama dan keberagaman dalam dua film masing-masing dari Malaysia dan Indonesia. Yang pertama adalah Wayang (2008, Malaysia) dan yang kedua Mencari Hilal (2015, Indonesia). Kedua film ini menarik karena kedua film tersebut berkisah tentang keberagaman agama dan budaya di masyarakat setempat. Esai ini akan mengeksplorasi dan menganalisis lebih jauh bagaimana beberapa aspek keberagaman dihadirkan dan ditampilkan di kedua film tersebut. Secara khusus, saya akan menganalisis bagaimana aspek tertentu dari keragaman dan agama digambarkan dalam dua film tersebut.

Pada bagian analisis saya, akan dimasukkan perbedaan regional dalam pengaruh penggambaran isu-isu ini pada dua film yang berbeda latar belakang budaya dan wilayah syuting film dilaksanakan.

\section{Tinjauan Pustaka}

Analisis film di sini akan menggunakan teori representasi yang dikemukakan oleh Stuart Hall. Hall berpendapat bahwa "Representasi adalah produksi makna melalui bahasa" (Hall, 1997). Representasi dalam pandangan Hall tidak berbicara tentang apakah penggambaran sesuatu itu akurat atau refleksi yang terdistorsi. Sebaliknya, Hall menekankan perbedaan makna dan interpretasi gambar yang pada dasarnya dibuat dalam film atau media. Di sini, Hall menegaskan tentang kompleksitas komunikasi yang dipandang meremehkan gagasan bahwa media memiliki pengaruh yang nyata dan kuat terhadap dunia. Dengan demikian, dalam pandangan Hall, tidak ada yang benar-benar mampu mempresentasikan gambaran aslinya dalam film melainkan hanya konstruksi realitas.

\section{Metodologi Penelitian}

Untuk membangun analisisnya, artikel ini menggunakan metode kualitatif. Itu juga menggunakan pendekatan komparatif. Penelitian ini adalah penelitian kualitatif-deskriptif dengan menggunakan analisis komperatif. Tipe penelitian komperatif menekankan pada aktivitas membandingkan dan menguraikan data-data yang bersangkutan satu sama lain dalam beberapa aspek untuk memperoleh hubungan, baik persamaan atau perbedaan.

Penelitian ini akan melakukan perbandingan antara film Mencari Hilal yang berlatar masyarakat tradisional Jawa di daerah Yogyakarta. Sebagian besar dialognya dalam Bahasa Indonesia, tapi terkadang juga menggunakan Bahasa Jawa dalam porsi kecil. Film lain yang dijadikan perbandingan adalah film Wayang yang berlatarkan sebuah desa di kawasan pantai timur, Kelantan, Malaysia. Dialek Melayu yang digunakan dalam film tersebut merupakan dialek bahasa Kelantan yang sangat berbeda dengan dialek Melayu kontemporer yang mirip.

\section{Hasil dan Diskusi}

Film Mencari Hilal merupakan bagian dari project yang digagas oleh Mizan Production yang mengusung tema Cinta Islam dan Indonesia Tanpa Diskriminasi oleh Studio Denny JA. Pembuat film ini berkomitmen untuk menghadirkan cerita perdamaian yang konstruktif dan menggambarkan Islam sebagai agama cinta yang penuh perdamaian. Film Mencari Hilal yang disutradarai oleh Ismail Basbeth dirilis pada 15 Juli 2015. Film yang dibintangi oleh Deddy Sutomo, Oka Antara, Erythrina Baskoro dan Torro Margens ini mendapat apresiasi dan perhatian yang besar dari publik baik nasional maupun internasional. Film ini telah ditayangkan di empat festival internasional antara lain International Premiere / Asian Future Competition Tokyo International Film 
Festival 2015, Hong Kong Asian Film Festival 2015, Sala Mindanaw International Film Festival, dan Jogja-NETPAC Asian Film Festival 2015 (Afrisia, 2015). Film yang diproduksi sebagai rangkaian kampanye Gerakan Islam Cinta dan Indonesia Tanpa Diskriminasi ini merupakan karya kolektif MVP Pictures, Studio Denny JA, Kitchen Film, Argi Film dan Mizan Productions.

Film Wayang yang disutradarai oleh Hatta Azad Khan mengisahkan tentang kehidupan masyarakat menjaga warisan kultural mereka yaitu tradisi wayang. Film yang dibintangi oleh Eman Manan, Ida Nerina, Piper Perabo, Wan Hanafi, Zul Huzaimy dan pendatang baru Mas Muharni ini dirilis pada 13 November 2008. Film ini diproduksi oleh Institut Riset dan Teknologi dan Fakultas Artistik dan Teknologi Kreatif. dari Universiti Teknologi Malaysia, dengan bantuan dan bentuk dukungan dari Perusahaan Pengembangan Film Nasional Malaysia (FINAS). Baru-baru ini, film tersebut secara resmi dipilih untuk Festival Film Asean TINGIN yang pertama (www.finas.gov.my).

Film Mencari Hilal berlatar dalam masyarakat tradisional Jawa di daerah Yogyakarta. Sebagian besar dialognya dalam Bahasa Indonesia, tapi terkadang juga menggunakan Bahasa Jawa dalam porsi kecil. Begitu juga dengan film Wayang yang berlatarkan sebuah desa di kawasan pantai timur, Kelantan, Malaysia. Dialek Melayu yang digunakan dalam film tersebut merupakan dialek bahasa Kelantan yang sangat berbeda dengan dialek Melayu kontemporer yang mirip.

Film Mencari Hilal adalah tentang menjaga tradisi yang sudah mulai menghilang. Dalam film ini, tokoh utama, Pak Mahmud diceritakan berusaha menapaki praktik-praktik tradisional yang dia anggap telah ditinggalkan dan tidak dipraktikkan di masyarakat. Tradisi itu adalah rukyatul Hilal (melihat Hilal). Inisiatif Pak Mahmud untuk "mencari Hilal" dilatarbelakangi oleh kritiknya terhadap pemerintah yang menghabiskan hingga 9 miliar rupiah untuk sebuah sidang isbat (diskusi antara pemerintah dan ormas Islam untuk menentukan Hilal). Praktek tradisi yang ditelusuri oleh Pak Mahmud tersebut adalah praktik Islam tradisional merupakan rangkaian kegiatan yang diselenggarakan untuk mengakhiri bulan Ramadhan dan menyambut bulan Syawwal. Hilal adalah istilah Arab yang berarti Bulan Sabit. Praktik Pak Mahmud dengan demikian merupakan bentuk praktik Islam tradisional. Ia mulai mencari Hilal dengan menelusuri jalan setapak yang panjang dan perjalanan menemui teman-teman lamanya untuk mencari lokasi menonton Hilal. Dalam perjalanannya, ia menemui berbagai fenomena masyarakat yang beragam.

Sementara itu, Film Wayang berkisah tentang menjaga tradisi turuntemurun dari tradisi lokal wayang. Berbeda dengan Mencari Hilal, Wayang merupakan bentuk perlawanan Pak Awang yang sematamata mempertahankan tradisi dan budaya yang tidak berkaitan langsung dengan pengalaman keagamaan. Sikap Pak Awang adalah moderat, baginya Wayang adalah seni pertunjukan untuk menghibur masyarakat. Tidak ada hubungannya dengan agama. Sikap Pak Awang merupakan bentuk sikap moderat saat berhadapan dengan Jusof yang menentang karyanya karena tergagap apa yang dilakukan Pak Awang sebagai bentuk politeisme. Meski Pak Awang sangat kuat dalam menjaga tradisi pewayangan, namun tidak membuatnya leluasa menerima inovasiinovasi baru seperti yang dilakukan oleh Awi. Awi mencoba berinovasi dengan memasukkan unsur budaya pop dan instrumen gitar untuk mengiringi penampilannya. Tapi Pak Awang tidak setuju dan menolak upaya Awi ini.

Dilihat dari konteks lokalitas komunitas tradisional kedua film ini, relatif tokoh utama direpresentasikan sebagai seseorang yang memiliki kedudukan dan peran dalam masyarakat dan keluarganya. Dalam film Mencari Hilal, Pak Mahmud adalah seorang bapak dalam tradisi masyarakat Jawa yang patriarkal. Masyarakat Jawa patriarkal merepresentasikan semangat yang kuat dimana sosok laki-laki harus dominan dalam ruang publik. Pak Mahmud sebagai pemeran utama merupakan sosok ayah, dan laki-laki yang muslim dan memiliki penguasaan atas aspek agama yang kuat di masyarakat. Selain sebagai pedagang, Pak Mahmud juga menjadi tokoh agama di lingkungannya. Hal ini membuat posisi Pak 
Mahmud relatif diuntungkan di tengahtengah masyarakatnya. Hal ini terlihat dari masyarakat yang cukup menghormati Pak Mahmud dengan menyebutnya "Ustadz". Ustadz adalah seseorang yang dianggap memiliki pemahaman agama namun tidak dapat disamakan dengan Kiyai. Di Jawa, Kiyai lebih tinggi dari Ustaz. Kiyai memiliki peran yang lebih luas dan biasanya Kiyai memiliki pesantren dan menjadi panutan di kalangan santri dan masyarakat umum. Sementara itu, aspek ekslusifitas agama dalam diri Pak Mahmud tidak terkesan dominan dibandingkan dengan. pak Awang dalam Film Wayang. Sebagai tokoh utama dalam Film, sosok Pak Awang sebagai lakilaki dan seorang ayah dapat dicitrakan dominan dalam tradisi masyarakat desa yang cenderung patriarki. Hal ini terwakili melalui perannya sebagai pemimpin kelompok seni wayang di daerahnya. Sebagai seorang pemimpin, Pak Awang memiliki pengaruh yang cukup besar di masyarakat. Otoritasnya dalam sani wayang diakui dalam masyarakat sekitarnya.

Dalam film Mencari Hilal, setting ini merepresentasikan tradisi budaya Muslim Yogyakarta pada khususnya. Setting ini juga merepresentasikan tradisi budaya Islam secara umum di Jawa. Yogyakarta adalah daerah basis Muhammadiyah terbesar di Indonesia. Disini, lahir dan berkembang mula-mula salah satu organisasi terbesar Islam Indonesia yaitu Muhammadiyah. Walau berbeda dengan tradisi Jawa umumnya yang bercorak tradisional NU. Namun dalam hal ini tradisi keagamaan tradisional antara NU dan tradisi Muhammadiyah dikaloborasi secara kompleks dalam film. Kompleksitas ini terlihat dalam beberapa representasi yang ditampilkan dalam film. Seperti aksi Pak Mahmud yang mencari Hilal pada dasarnya adalah bentuk praktik keagamaan di NU, "ruk'yatul hilal" atau melihat hilal adalah tradisi yang umum dipraktikkan begitu pula Kirab. Kementerian Agama, tetap menjadikan "rukyatul hilal" sebagai metode penentuan awal dan akhir Ramadhan. Di sisi lain, Pak Mahmud juga menentang beberapa praktik yang dianggap bertentangan dengan agama dan dianggap bidah seperti melaksanakan puasa berdasarkan kalender jawa
Sedangkan pada Film Wayang, setting ini merepresentasikan tradisi budaya masyarakat pedesaan di Kelantan. Kelantan dianggap sebagai negari Muslim yang dominan di Malaysia. Kelantan, negara bagian utara Terengganu, diperintah oleh partai politik Islam (PAS) (Heide, 2002). Dalam analisanya terhadap film ini, Riddle secara tegas menyebut bahawa film ini juga menjelaskan secara terbuka jendela ketegangan antara seni Islam konservatif dan Islam yang dipromosikan oleh PAS (Partai Islam Malaysia) yang berkuasa di Kelantan sejak tahun 1990 (Riddell, 2009).

Secara simbolik, representasi Islam yang dihadirkan dalam kedua film ini sangat jelas. Dalam Film Mencari Hilal Pak Mahmud terlihat sangat tradisional dengan kerudung hitam, kemeja koko, celana tiga perempat. Dalam konteks representasi politik, terlihat dari kemunculan Pak Mahmud yang merepresentasikan komunitas tradisional Nahdlatul Ulama (NU). Tokoh Pak Mahmud mengingatkan para pemuka agama NU seperti KH. Abdurrahman Wahid, KH. Mustafa Bisri dan kiai NU pada umumnya. Ini memberi kesan bahwa Pak Mahmud berasal dari pesantren. Representasi kostum dan aspek budaya juga terlihat dari karakter Heli dan Halida, putra putri Pak Mahmud. Tidak diketahui mengapa dia tidak berperilaku seperti ayahnya. Kemungkinan besar disebabkan oleh Heli berpendidikan modern. Hal tersebut bisa diketahui ketika Heli tidak bisa memahami percakapan ayahnya saat membicarakan masalah agama. Hal ini menunjukkan bahwa budaya Jawa modern telah membuat Mahmud terbuka dengan perubahan masyarakat. Begitu pula dengan keseharian Halida yang berjilbab dan mengenakan celana dalam pekerja sebagai wanita pekerja bisa dibilang orang yang cukup maju jika dibandingkan dengan aktivitas wanita pada umumnya di masyarakat pedesaan. Dapat dicatat bahwa dalam keluarga Mahmud sendiri, tidak ada pertanyaan tentang peran perempuan di luar urusan rumah tangga. Sebagai sebuah genre film yang ditayangkan pada masa setelah reformasi. Penggambaran tentang maskulinitas Muslim dan posisi perempuan 
nampak berbeda dengan film yang diproduksi sebelum reformasi. Film Mencari Hilal memberikan gambaran tentang laki-laki muslim yang urban dan perempuan yang mulai digambarkan menempati ruang-ruang publik (Woodrich, 2018).

Dalam Film Wayang, Pak Awang mewakili masyarakat umum dan masyarakat biasa yang memakai kemeja batiknya yang khas. Dia tidak banyak menonjolkan sisi religiusnya. Namun, gambaran simbol agama muncul dalam tokoh Yusof yang digambarkan memiliki hiasan kepala berwarna putih dan mengenakan busana klasik Islami. Lebih lanjut, Riddle mengasosiasikan gambaran Yusof ini kepada Nik Abdul Aziz Nik Mat, Kepala Menteri Klantan dan kepala Spiritual PAS. Kode pakaian yang berbeda-beda ditransfer ke dua anak antagonis itu: Yusof meminta kedua putranya mengenakan kopiah Islami, sementara Awang mengizinkan Melor untuk menata rambutnya tanpa penutup kepala Islami(Riddell, 2009).

Jika Pak Mahmud mengenakan pakaian adat pesantren, bukan berarti pandangan Pak Mahmud mewakili tradisi Islam tradisional NU. Dalam kesehariannya Pak Mahmud selalu menampilkan nilai-nilai keislaman baik dari tingkah laku maupun tutur katanya, Pak Mahmud dapat dijadikan contoh praktik Islam normatif yang berorientasi pada syariah. Pak Mahmud kerap mempertanyakan persoalan tradisi dan praktik keagamaan yang kerap dianggapnya sesat. Beberapa konflik yang terjadi antara lain melibatkan dirinya dengan para pedagang di pasar. Niatnya untuk berdagang adalah orientasi bisnis tetapi menganggapnya sebagai tindakan ketundukannya kepada Tuhan. Dalam kehidupan sehari-harinya, Pak Mahmod sering mengutip pesan-pesan Islami dan sering melakukan segala sesuatu sesuai dengan ajaran normatif Islam. Pada suatu hari, dia dibenci oleh pedagang lain karena menjual barang dengan harga termurah.

Posisi Pak Mahmud dapat dikatakan sebagai penganut Islam tradisional. Hal ini terlihat jelas saat terjadi perbincangan antara Pak Mahmud dan Heli saat berdebat tentang mencari Hilal. Heli berkata: "Kenapa kamu masih ingin mencari Hilal, sekarang zaman sudah maju kita bisa menggunakan GPS untuk mencari alamat apapun". Membaca debat keduanya, seolah mengilustrasikan debat antara NU dan Muhammadiyah di Indonesia. NU yang selalu mempertahankan metode rukyat hilal dalam menentukan awal dan akhir bulan puasa, sedangkan Muhammadiyah mengaku mengetahui waktu dan pecahan bulan hijriyah berdasarkan cara hisabnya (Metode Hisab). Dua corak pemikiran dan pandangan ini dianggap mewakili dua kutub dominan dalam tradisi Islam di Indonesia yaitu konservatif dan modernis.

Memposisikan Pak Mahmud di antara Islam Jawa tradisional murni sedikit dilema. Di satu sisi Pak Mahmud sangat kuat dalam mempertahankan tradisi Islam tradisionalnya, namun seringkali Pak Mahmud juga melihat bid'ah dari beberapa praktik keagamaan seperti masyarakat yang menyelenggarakan puasa berdasarkan kalender Jawa. Mereka masih menggunakan penanggalan Jawa. Beberapa sarjana Islam di Jawa seperti Geertz (1967) dan Beatty (1999) menganggap model praktik ini sebagai sinkretisme, ketika Woodward (2010) dan Ricklefs (2006) menganggapnya sebagai bagian dari ekspresi mistik Islam. Gambaran masyarakat yang dijumpai oleh Pak Mahmud dalam perjalanan umumnya menyangkut isu Islam tradisional yang diwakili oleh NU dan Islam puritan yang diwakili oleh Muhammadiyah.

Keberadaan NU, Muhammadiyah dan banyak organisasi Muslim arus utama lainnya di seluruh Indonesia adalah ciri khas Islam Indonesia lainnya. Organisasi Muslim ini non-politik, beroperasi tidak hanya sebagai organisasi keagamaan tetapi juga sebagai organisasi sosial, budaya, dan pendidikan. (Azra, 2013). Pada dasarnya, dua tradisi ini memiliki corak pandangan keagamaan yang berbeda satu sama lain. Jika tradisi Muhammadiyah lebih menonjolkan aspek formal ajaran Islam, maka Tradisi NU sendiri lebih menonjolkan sikap mempertahankan tradisi dan ajaran agama dari generasi ke generasi (Burhani, 2013).

Dalam film Mencari Hilal banyak representasi religius yang ditampilkan dalam film tersebut. Selain dinamika antara Islam tradisional dan Islam puritan. Ada pula 
perwakilan ormas Islam yang menyerang jemaah Kristen yang melakukan ibadah dan Politik Islam diwakili oleh Pak Arifin sebagai pemuka agama yang gagal mencalonkan dirinya sebagai bupati di suatu daerah. Representasi Islam radikal dihadirkan dalam polemik relasi Islam dan Kristen dalam komunitas desa yang heterogen. Peristiwa pertama sebelum perjalanan terjadi saat perjalanan dilanjutkan, mereka bertemu dengan sekelompok pemuda yang mengendarai sepeda motor yang menarik perhatian publik. Mereka berpakaian dengan simbol Islam sambil berteriak dan menggelegar kendaraan mereka. Heli langsung memprotes dan ayahnya membela tingkah laku mereka sambil berkata: "Niat mereka baik, mengingatkan semua orang agar tidak salah seperti kamu". Pertemuan Pak Mahmud dengan kelompok Islam radikal ini kembali terjadi ketika Pak Arifin dalam perjalanannya juga bertemu dengan seorang Kristen non-Muslim yang mengajaknya bertemu dengan seorang pendeta yang sedang berdakwah di hadapan jamaahnya. Umat Kristen beribadah di halaman, cukup ramai yang datang dari luar kampung. Namun, tiba-tiba datang beberapa kelompok orang yang berbaju muslim, berjubah dan membawa benda tumpul. Mereka berteriak dan mengusir jamaah yang sedang beribadah. Mereka tidak setuju dengan kegiatan ibadah umat Kristen di sana karena dianggap tidak memiliki izin. Komentar mereka: "Ibadah ini tidak sah menurut hukum, karena tidak ada IMB, merugikan umat dan melanggar hukum". Representasi persoalan kebebasan beragama di Indonesia merupakan persoalan yang aktual sejak masa reformasi. Berbagai laporan menyebutkan tentang kelompok minoritas Islam yang cenderung bersikap keras dan radikal serta intoleran. Hal ini bertentangan dengan semangat moderasi beragama masyarakat Muslim mayoritas pada umumnya.

Potret keberagaman ekspresi keagamaan dalam Mencari Hilal di atas menyajikan kepada kita berbagai bentuk konteks religi masyarakat Indonesia, khususnya di Jawa. Di antara yang paling banyak ditemukan adalah ekspresi Islam moderat yang diwakili oleh Islam Tradisional (NU) termasuk masyarakat desa yang masih mengamalkan ajaran agama leluhur murni dan Islam puritan (Muhammadiyah) yang cenderung lebih simpel dalam ibadah dan praktik amalan keagamaanya. Selain itu, film ini juga merepresentasikan kelompok minoritas seperti Islam radikal yang diwakili oleh beberapa ormas Islam dan juga ekspresi Politik Islam. Namun, kategori ini tidak selamanya bersifat tetap dan ketat, dalam kondisi tertentu, praktik pengamalan masyarakat Indonesia cenderung sangat fleksibel dan dinamis. Hal ini nampak dalam beberapa praktik keagamaan masyarakat antara masyarakat yang ada di pedesaan dan masyarakat di perkotaan. Dalam Film,

Dalam film Wayang, perlawanan agama diwakili oleh Jusof yang konservatif dan putra Pak Awang. Apa yang dilakukan oleh Jusuh dan anak pak Awang itu merepresentasikan Islam yang konservatif. Sedangkan Islam moderat ditampilkan oleh sepupu Awang yang sependapat dengan praktik keagamaan Pak Awang. Konsep Islam yang ditunjukkan oleh sepupu Awang dalam film tersebut juga kental ketika sepupunya melakukan praktik silat tradisional. Hal ini dengan jelas menegaskan bahwa model ekspresi Islam yang tidak mempersoalkan praktik tradisional biasanya selalu berusaha untuk mempertahankan tradisi mereka.

Ini sedikit berbeda dengan konteks keagamaan di Malaysia. Menurut Peter Ridell saat mengomentari aksi dan debat seputar konflik tokoh utama antara Awang dan Yusoh sebagai wujud promosi gagasan antara UMNO yang mengusung nilai-nilai substantive Islam dan PAS yang mengusung aspek normatif Islam. Riddell mencontohkan perkawinan antara istri Awaang yang menentang suaminya membawa dua anak yatim piatu (Awi dan Melur) ke rumahnya, Awang menjawab dengan mengatakan bahwa istrinya tidak memiliki simpati dan rasa sakit. Menurut Riddell, Awang melambangkan representasi Muslim Modern di Malaysia yang mengedepankan pengutamaan nilainilai Islam. Sedangkan Yusof dinilai sangat memperhatikan aspek hukum Islam dengan memaksa kedua anaknya memakai peci islami. Contoh lain yang dibahas Riddell adalah ketika perdebatan antara hukum wayang kulit dan tanggapan Awang ketika ia berencana menjadikan Melur sebagai istri keduanya. (Riddell, 2009). Di medan 
diskursif, perdebatan wacana tentang peran Islam dalam urusan politik, telah membentuk batas-batas wacana politik antara UMNO dan PAS bersama isu-isu seperti negara Islam, hukum hudud dan bahkan soal pakaian Islami (Liow, 2004). Ciri yang kuat tergambar dalam dua karakter yang masing-masing mewakili pandangan Islam konservatif dan Islam reformis. Representasi citra politik Islam yang digambarkan dalam film ini memuat pesan tentang perlawanan agama dan tradisional dalam konteks masyarakat lokal.

\section{Kesimpulan}

Dua film yang masing-masing mewakili film dengan corak keagamaan yaitu Mencari Hilal dan Wayang telah menghadirkan representasi keberagaman di Indonesia dan Malaysia. Dua film ini sama-sama memotret ekspresi keberagamaan masyarakat dalam struktur dominan Islam sebagai agama mayoritas di kedua negara. Dua film yang teliti merupakan corak baru dalam konteks perkembangan budaya popular di kedua Negara. Kedua Hal ini sekaligus menegasakan bahwa penggambaran realitas pluralisme etis dan keagamaan di kedua Negara sebagai sebuah perkembangan Islam yang dominan dalam kurun beberapa dekade belakangan. Hal ini berbeda dengan masa sebelumnya dimana Islam cenderung bersifat umum di bawah bayang-bayang pengaruh otoritarianisme di kedua Negara.

Di produksi pada tahun 2014, jelas terlihat bahwa dalam film Mencari Hilal, digambarkan representasi Islam Indonesia yang bervariasi baik dalam tradisi maupun ekspresi. Namun pesan yang ingin disampaikan adalah mencintai sesama dan menghargai perbedaan. Hampir dinamika Islam Indonesia ditampilkan dalam film ini, namun pesan utama dari film tersebut seolah menegaskan bahwa masyarakat Indonesia yang dominan adalah masyarakat yang berpikiran moderat yang diwakili oleh NU dan Muhammadiyah, sedangkan bentuk ekspresi politik Islam seperti konservatif, Gerakan radikal dan ekstrim tidak mampu menyentuh aspek paling fundamental dari masyarakat Indonesia. Dalam film ini, debat tentang Hilal merepresentasikan debat antara dua ormas Islam yang dominan di Indonesia, yakni NU moderat dan Muhammadiyah. Di sisi lain, film ini juga memotret persoalan toleransi beragama yang menjadi isu yang problematis di Indonesia khususnya sejak masa reformasi.

Sementara itu, Film Wayang juga menunjukkan kompleksitas keberagaman Malaysia sebagai sebuah etnis melayu dan Islam sebagai agama resmi Negara. Dalam film Wayang, representasi agama dan keragaman dihadirkan dalam yang nampak dalam polemik antara dua kutub agama yaitu tradisional dan reformis. Selain itu, film tersebut juga menggambarkan representasi dominasi pandangan Islam konservatif dan Islam reformis dalam masyarakat Melayu yang terus dinamis dan berpengaruh pada konteks politik, sosial dan budaya. Film ini sekaligus mampu memotret pengaruh dominasi corak keislaman tersebut dalam konteks kultural masyarakat pinggiran dan marjinal dalam struktur dominan Melayu Islam. Representasi yang dihadirkan adalah nilai-nilai budaya melayu yang dianggap bertentangan dengan Islam di satu sisi dan masyarakat tetap menjaga nilai-nilai budaya tanpa kehilangan identitas mereka sebagai muslim dan Melayu.

\section{Daftar Pustaka}

Afrisia, R. S. (2015). Dinamika Muslim Indonesia "Mencari Hilal" Keliling Asia. Diambil 30 Oktober 2017, dari https://www.cnnindonesia.com/hiburan/2 0160928161542-220-161854/dinamikamuslim-indonesia-mencari-hilal-kelilingasia/

Azra, A. (2013). Distingusing Indonesia Islam: Some Lessons to Learn" in Burhanuddin, Jajat and Kees Van Dijk (Islam in Indonesia: Contrasting Images and Interpretations). Amsterdam: Amsterdam University Press.

Burhani, A. N. (2013). Defining Indonesian Islam An examination of the construction of the national Islamic identity of traditionalist and modernist Muslims" in Burhanuddin, Jajat and Kees Van Dijk (Islam in Indonesia: Contrasting Images and Interpretations). Amsterdam: Amsterdam University Press.

Dominic Strinati. (2005). Popular Culture: Pengantar Menuju Teori Budaya Populer. Yogyakarta: Ar-Ruzz. 
Hall, S. (1997). Representation: Cultural Representation and Signifying Practice. London: Sage Publication.

Heide, W. V. D. (2002). Malaysian Cinema, Asian Film. Amsterdam: Amsterdam University Press.

Liow, J. C. (2004). Political Islam in Malaysia: Problematising discourse and practice in the UMNO-PAS 'Islamisation race.' Commonwealth \& Comparative Politics, 42(2), 184-205. https://doi.org/10.1080/14662040420002 99254

Riddell, P. G. (2009). A Film Window into Political Struggle in Malaysia. Indonesia and the Malay World, 37(109), 397-400. https://doi.org/10.1080/13639810903269 367

Turner, G. (1988). Film as Social Practice. London and New York: Routledge.

Woodrich, C. A. (2018). Representing Islam in Indonesian Film Advertising during the Suharto Era (1966-1998) and Reform Era (1998-Present). Komunikator, 10(2), 60-74. https://doi.org/10.18196/jkm.101006 